\title{
Impact of different processing methods on phytochemicals and anti-oxidative properties of five varieties of Mushrooms.
}

\author{
*R. Kaur, M. Verghese, S. Willis, L.T. Walker \\ Nutritional Biochemistry and Carcinogenesis Laboratory, Department of Food and Animal Sciences, Alabama A\&M University, \\ Normal, AL 35762 \\ DOI: 10.29322/IJSRP.12.01.2022.p12115 \\ http://dx.doi.org/10.29322/IJSRP.12.01.2022.p12115
}

\begin{abstract}
Mushrooms are rich in vitamin D, antioxidants, and phenolic compounds. Different processing techniques may be used to increase shelf life and reduce spoilage of mushrooms. The objective of this study was to determine total phytochemical and total antioxidant activity of extracts of five varieties (Portabella, White Button, White Beech, Oyster \& Seafood) of mushrooms (fresh, oven dried \& sautéed). The antioxidant activity was measured by 2,2-diphenyl-1-picrylhydrazyl radical solution (DPPH), ferric reducing antioxidant power (FRAP), Trolox equivalence antioxidant capacity assay (TEAC), and nitric oxide radical scavenging activity (NORS). All samples were freeze-dried followed by preparation of methanol extracts. Oven dried and cooked Portabella, and Oyster Mushrooms had lower total phenolic (295.05 and $135.54 \mu \mathrm{g} \mathrm{GAE} / 100 \mathrm{~g} \mathrm{DW})$ compared to sautéed (417.49 $\mu \mathrm{g} \mathrm{GAE} / 100 \mathrm{~g} \mathrm{DW}$ ) and raw (446.95 and $309.28 \mu \mathrm{g} \mathrm{GAE} / 100 \mathrm{~g}$ DW). Sautéed Portabella (111.97 $\mu \mathrm{g}$ C.E/100g DW) and Oyster samples had higher total flavonoid content compared to fresh $(81.45$ and $64.70 \mu \mathrm{g}$ C.E/100g DW) and oven dried (72.38 and $66.45 \mu \mathrm{g}$ C.E/100g DW) samples. Highest FRAP activity was observed in raw Portabella (3.94 mM Fe(II)/100g DW) and Oyster extracts (2.62 mM Fe(II)/100g DW) compared to sautéed samples $(3.03 \mathrm{mM} \mathrm{Fe}(\mathrm{II}) / 100 \mathrm{~g} \mathrm{DW})$ with 1.3 times lower activity. Followed by 1.9 folds reduced FRAP activity in oven-dried Portabella $(2.07 \mathrm{mM} \mathrm{Fe}(\mathrm{II}) / 100 \mathrm{~g} \mathrm{DW})$, and 1.69 folds' lower action in oven-dried Oyster $(1.55 \mathrm{mM} \mathrm{Fe}(\mathrm{II}) / 100 \mathrm{~g} \mathrm{DW})$. All the Portabella treatments had 1- 2.5 folds higher total phenolic, flavonoid content and FRAP activity compared to Oyster mushrooms. Future research will include using the extracts for the prevention of chronic disease studies. Data from this study will be helpful to determine the processing conditions which will maximize phytochemicals and antioxidants with implications in the development of functional food products.
\end{abstract}

Keywords- Phytochemical, Scavenging, Radical, Antioxidants, Functional

\section{Introduction}

Most chronic diseases have been found to be diet related, therefore, diet may play an important role in the prevention of these diseases. Functional foods come into play when looking at prevention of these diseases. Foods that contain antioxidants, minerals, vitamins, omega-3 fatty acids, or even dietary fiber may be considered functional foods and may play a role in reducing the risk of chronic diseases (Lobo, Patil, Phatak, \& Chandra, 2010b). Many of these bioactive compounds are found in plants, edible fungi as well as in oils from marine animals. Thus, we need functional ingredients from both plant and animal's sources (Shahidi, 2004). Studies by Arts \& Hollman (2005), Winston \& Beck (1999) have reported various biological effects related to the consumption of foods rich in polyphenols. These phenolic compounds may be beneficial in reducing the risk associated with chronic diseases such as diabetes and cancer (Sabu, 2002). Mushrooms have been consumed for thousands of years for their nutritional and medicinal properties because of the presence of essential fatty acids, proteins, vitamins and minerals and very low calories (Agrahar-Murugkar and Subbulakshmi, 2005; Manzi et al., 2004; Pereira et al., 2012; Sanmee et al., 2003; Reis et al., 2012). Essential amino acids are leucine, lysine, isoleucine, valine, methionine, pheylalanine, threonine and tryptophan. Essential fatty acids present in mushrooms are polyunsaturated fatty acids, linoleic acid, $\alpha$-linoleic acid, omega-3, 6 and 9 (Caglarirmak, 1999). Water soluble and fat-soluble vitamins thiamine, riboflavin, pyridoxine, cyanocobalamin, pantothenic acid, niacin, folic acid, vitamin C, A (retinoic acid), D (cholecalciferol), E (tocopherol) and K (phylloquinone) (Caglarirmak, 1999) are found. Essential minerals present are $\mathrm{Ca}, \mathrm{P}, \mathrm{Na}, \mathrm{K}, \mathrm{Cl}, \mathrm{Mg}, \mathrm{Mn}, \mathrm{S}, \mathrm{Fe}, \mathrm{Cu}, \mathrm{I}, \mathrm{Zn}, \mathrm{F}, \mathrm{Cr}, \mathrm{Se}$, Mo, and Si. (Caglarirmak, 1999). Different nutraceuticals can be obtained from mushrooms due to the presence of number of unsaturated fatty acids, vitamins, and minerals. These bioactive compounds present in mushrooms can also show additive and synergistic effects, therefore, can be incorporated directly in the diet (Barros et al., 2007 \& 2008; Ferreira et al., 2009; Pereira et al., 2012; Vaz et al., 2010). Their medicinal properties have been reported such as anti-tumor and immunomodulating effects (Ferreira et al., 2010), inhibition of platelet aggregation (Hokama and Hokama, 1981), reduction of blood cholesterol concentrations (Jeong et al., 2010), prevention or alleviation of heart disease and reduction of blood glucose levels (Jeong et al., 2010), and antimicrobial activity

This publication is licensed under Creative Commons Attribution CC BY. 
(Hirasawa et al., 1999). Some of these medicinal properties are attributed to bioactive products with antioxidant activity such as phenolic compounds and ergothioneine a sulfur containing amino acid (Ferreira et al., 2009; Barros et al., 2009; Tanret, 1909). Ergothioneine is found in human body but the specific role of is not known, it is highly concentrated in red blood cells, semen, kidneys and liver. It is believed to have a significant role in human health due to specific transporters for ergotheioneine in many tissues (Grundemann, 2012; Grundemann et al., 2005). Ergotheioneine is known to have antioxidant properties and help maintain the glutathione levels by interacting with other cellular defense systems during oxidative stress (Glustarini, Rossi, Milzani, Colombo \& Dalle- Donne, 2004; Arduini, Eddy \& Hochstein, 1990). Grieve (1975), proposed that the increased generation of oxygen species or a decrease in the antioxidant defense capability results in oxidative stress in cells and tissues. Oxidative stress suggests an imbalance in the antioxidant defense mechanisms and the production of Reactive Oxygen Species (ROS). ROS include radicals such as $\mathrm{OH} \cdot$, $\mathrm{RO} 2 \cdot \mathrm{NO} \cdot$ and $\mathrm{O} 2 \cdot-$ and non-radicals such as $\mathrm{HOCl}, \mathrm{O} 2, \mathrm{ONOO}-, \mathrm{O} 3$, and $\mathrm{H} 2 \mathrm{O} 2$. The antioxidant defense system is a complex network of antioxidants such as vitamins $\mathrm{A}, \mathrm{C}$, and E, glutathione, and enzymes (catalase, glutathione peroxidase, superoxide dismutase and glutathione reductase) (Feher, 1987; Polidori, 2001). The antioxidant defense system protects the body against the adverse health effects caused due to formation of free radical species (Halliwell, 1994). Phenolic compounds may act as antioxidants against free radicals and reactive oxygen species (Lima et al., 2006). Fruits and vegetables have been studied for their antioxidant properties due to the presence of phytochemicals such as phenolic compounds (Tomás-Barberán et al., 2001). Polyphenols may induce endogenous antioxidant enzymes by activating gene expression or by affecting signal transduction (Becker, Nissen, \& Skibsted, 2004). The major phenolic compounds present in mushrooms are protocatechuic acid, p-hydroxy benzoic acid, p-coumaric acid and cinnamic acid (Reis et al., 2012). Research (Kalaras, Beelman \& Elias, 2012; Kalaras, Beelman, Hollick \& Elias, 2012) show that mushroom is an abundant source of vitamin D2 depending on the amount of light subjected during cultivation. Vitamin $\mathrm{D}$ is present in the form of provitamin, and its content may vary depending on the cultivation conditions. The mushrooms exposed to sunlight, or the wild mushrooms have high amount of vitamin D2 while the mushrooms cultivated in the dark have very low or no vitamin D. This is because most of the fungi produce ergosterol which is a precursor to vitamin D2, under sunlight or UV radiations (Mattila et al., 2001). A study by Lin et al. (2007), suggested a reduction in the development of breast cancer among postmenopausal women with higher intakes of calcium and vitamin D. Some of the other experimental studies (Jacobson et al., 1989; Xue et al., 1999; Richter et al., 1995; Carroll at al., 1991) performed on animals' associate prevention of breast cancer to the intake of calcium and vitamin D. Female rats when fed with adequate amounts of calcium and vitamin $\mathrm{D}$ had significantly lower production of mammary tumors in comparison to the female rats fed a diet containing insufficient amounts of calcium and vitamin D. Studies (Xue et al., 1999; Richter et aal., 1995) used a high fat diet to induce adverse changes in mammary glands, which were reduced by intake of diet with higher calcium and vitamin D. A study by Manzi et al. (2004) suggest higher total phenolic content than fresh and frozen mushrooms. Some processing methods are known to enhance and some to reduce the antioxidant activity and certain phenolic compounds of Mushrooms. Hence, this study will focus on the effect of temperature and cooking time variable on bioactivity of mushrooms.

\section{Justification}

Mushroom has a high potential for their use in the prevention of diseases because of the presence of bioactive compounds present in mushrooms but are perishable and have a short shelf life. Different processing techniques such as sautéing, oven drying, land freeze-drying may be used to increase the shelf life of mushrooms by reducing spoilage post-harvesting. However, there is no data regarding effects of different processing methods with time and temperature variables on the bioactivity of Mushrooms. Therefore, there is a need to conduct research on the impact of temperature and time variable on bioactivity of most consumed mushrooms for nutritional, medicinal and nutraceutical purposes.

\section{Hypothesis}

Processing will increase the phytochemical content and antioxidative properties of Mushrooms.

\section{Objective}

To determine the total phytochemical and total antioxidant activity of extracts of selected varieties of mushrooms as measured by 2,2-diphenyl-1-picrylhydrazyl radical solution (DPPH), ferric reducing antioxidant power (FRAP), Trolox equivalence antioxidant capacity assay (TEAC), total antioxidant capacity (TAC), and nitric oxide radical scavenging activity (NORS).

\section{Materials and Methods}

\subsection{Instrumentation}

Freeze dryer (VirTis Genesis 35L SpScientific, Warminister, PA), conventional Oven (Isotemp Oven, Fisher Marietta OH, model 6925), waring blender (Model no. 31BL92, New Hartford, Connecticut, US), sonicator (Bransonic M5800H, Branson 5800, Branson Ultrasonics corporation, Danbury, CT 06810, USA), centrifuge (Survall Legend XTR centrifuge, Thermofischer Scientific), rotary evaporator (Buchi Rotavapor R-215, USA), Synergy HT microplate reader (BioTek Instruments, Inc.; Synergy MTX multimode reader, S1LFA; Highland Park, Winooski; VT).

\subsection{Sample Preparation}


Fresh mushrooms (Portabella, White Button, Seafood, White Beech, Oyster, and Shitake) were obtained from a local food store, Huntsville, Alabama, US. The mushrooms were washed, diced, and freeze-dried (VirTis Genesis 35L Sp Scientific, Warminster, PA). Mushrooms were cleaned, sliced, and placed in an oven for drying (Isotemp Oven, Fisher Marietta $\mathrm{OH}$, model $6925)$ at $200^{\circ} \mathrm{F}$ until dry $\left(10 \%\right.$ moisture). Mushrooms were washed, sliced, and sauteed in a pan on stove top at $80^{\circ} \mathrm{C}$ for 10 minutes until their color changed to a golden brown and then frozen at $-80^{\circ} \mathrm{C}$ following which they were placed in a freeze dryer (VirTis Genesis 35L Sp Scientific, Warminster, PA). Dried mushrooms were ground into a fine powder using a Waring blender (Model no. 31BL92, New Hartford, Connecticut, US) before extraction.

\subsection{Preparation of Methanol extracts \& Aqueous extracts}

Methanol extracts (ME) were prepared following the method developed by Amazu et al. (2010) with slight modifications. A known quantity of freeze-dried mushroom powder was soaked in $80 \%$ methanol with continuous shaking following which the samples were sonicated (Bransonic M5800H, Branson 5800, Branson Ultrasonics Corporation, Danbury, CT 06810, USA) at input frequency $50-160 \mathrm{~Hz}$ and output frequency $40 \mathrm{KHz}$ for 60 minutes. Aqueous extracts were prepared using the same method. A known quantity of freeze-dried mushroom powder was soaked in hot distilled water with continuous shaking following which the samples were sonicated (Branson M5800H, Branson Ultrasonics Corporation, Danbury, CT 06810, USA) at input frequency 50$160 \mathrm{~Hz}$ and output frequency $40 \mathrm{KHz}$ for $60 \mathrm{~min}$. Both the aqueous and methanol extracts were centrifuged (Survall Legend XTR centrifuge, Thermofischer Scientific) at $10000 \mathrm{~g}$ for 15 minutes. Supernatants were filtered using a Whatman filter paper, and the filtrate was evaporated to dryness at $50^{\circ} \mathrm{C}$ using a rotary evaporator (Buchi Rotavapor R-215, USA). The concentrate was stored at $-20^{\circ} \mathrm{C}$ until further use.

\subsection{In Vitro Chemical Analysis}

\subsubsection{Total Phenolic Content}

Total polyphenols were determined following the Folin-Ciocalteu's method with slight modifications (Gajula et.al, 2009).

\subsubsection{Total Flavonoid Content}

Flavonoid content was determined (Marinova, Ribarova, \& Atanassova, 2005) using an aluminum chloride colorimetric assay and catechin as a standard.

\subsubsection{FRAP (Ferric Reducing Antioxidant Potential)}

The FRAP (Ferric Reducing Antioxidative Potential) assay was conducted using the method developed by Benzie \& Strain (1996) with slight modifications using FeSO4.7H2O standard.

\subsubsection{TEAC (Trolox Equivalent Antioxidant Capacity)}

TEAC of extracts was determined using a colorimetric assay suggested by Miller et al., (1996) with slight modifications.

\subsubsection{NORS (Nitric Oxide Radical Scavenging)}

Modified Griess Illosvoy reagent (Sakat, Juvekar, \& Gambhire, 2010) assay protocol was used to determine the nitric oxide scavenging activity.

\section{Results \& Discussion}

\subsection{Total Phenolic Content}

The antioxidant properties of phenolic compounds are based on their redox reaction potential, which plays a crucial role in the neutralization of free radicals (Bhaskar \& Balakrishnan, 2009). Phenolic compounds reduced the FC reagent resulting in the formation of a blue color, which was measured at $750 \mathrm{~nm}$ against a Gallic acid standard. Table 1 shows Total Phenolic Content (TPC) in five varieties [Portabella (P), Oyster (O), White Button (WBt), Seafood (SF), and White Beech (WBh)] of mushrooms with three different treatments fresh freeze-dried (F), sautéed freeze-dried (S) and oven-dried freeze-dried (OD) dissolved in two different solvents aqueous (A) and methanol (M). There was significant $(\mathrm{p}<0.0001)$ three-way interaction for VARIETY X EXTRACTION SOLVENT X TREATMENT. The extraction solvent, treatment method, and the varieties of mushrooms had significant differences in the quantity of phenols in the samples. 
Total Phenolic Content of Portabella mushrooms was significantly $(\mathrm{p} \leq 0.05)$ higher in aqueous sautéed (AS) (24.44 mg Ferulic acid/100g DW) than aqueous fresh freeze-dried (AF) and aqueous oven dried (AOD) extracts (22.17 and $20.34 \mathrm{mg}$ Ferulic acid/100g DW). Similar results were obtained in Oyster (AS- 33.57 mg F.A. /100g DW, AF- $25.20 \mathrm{mg}$ F.A. /100g DW, and AOD- 15.84 mg F.A. /100g DW) White Button (AS- $6.95 \mathrm{mg}$ F.A. /100g DW, AF- $5.96 \mathrm{mg}$ F.A. $/ 100 \mathrm{~g}$ DW, and AOD- $5.74 \mathrm{mg}$ F.A. /100g DW), Seafood (AS- $8.74 \mathrm{mg}$ F.A./100g DW, AF- $6.00 \mathrm{mg}$ F.A. /100g DW, and AOD- $4.63 \mathrm{mg}$ F.A. /100g DW) and White Beech (AS- 5.15 mg F.A. /100g DW, AF- $4.30 \mathrm{mg}$ F.A./100g DW, and AOD- $5.20 \mathrm{mg}$ F.A. /100g DW). Whereas TPC for Portabella mushrooms was significantly $(\mathrm{p} \leq 0.05)$ higher in methanol fresh freeze-dried (MF) (7.33 mg F.A./100g DW) compared to methanol sautéed freeze-dried (MS) and methanol oven-dried freeze-dried (MOD) extracts (4.61 and 4.48 mg F.A./100g DW).

Similarly, TPC was significantly $(\mathrm{p} \leq 0.05)$ lower in heat treated samples of Oyster (MF- $8.04 \mathrm{mg}$ F.A./100g DW, MS- 5.97 mg F.A./100g DW, MOD- 4.45 mg F.A./100g DW), White Button (MF- 5.35 mg F.A./100g DW, MS- 4.97 mg F.A./100g DW, MOD- 4.85 mg F.A./100g DW), Seafood (MF- 4.48 mg F.A./100g DW, MS- 4.02 mg F.A./100g DW, MOD- 3.97 mg F.A./100g DW) and White Beech (MF- $3.82 \mathrm{mg}$ F.A./100g DW, MS- $3.33 \mathrm{mg}$ F.A./100g DW, MOD- $3.04 \mathrm{mg}$ F.A./100g DW) mushrooms. Methanol extracts for all five varieties of mushrooms showed lower TPC than the aqueous extracts in their respective treatment methods. Among all the varieties of mushrooms, Oyster mushrooms had significantly $(\mathrm{p} \leq 0.05)$ higher TPC followed by Portabella, White Button, Seafood, and White Beech Mushrooms.

Some studies on the retention of total phenolic content in mushrooms, stated that cooking procedures that involve heating lower the phenolic content by destruction of the structure of phenolic compounds present in mushrooms (Khalil and Mansour, 1995; Barros et al., 2007). However, a study by Ju et al. (2010) had shown increase in the soluble phenolic acid content of Chaga mushroom when steamed with pressure. A study by Sun et al. (2014) had shown that microwaving increased and boiling decreased the phenolic content in Boletus mushroom varieties. The factors such as nature of plants, temperature, and polarity of the solvent along with the extraction method used may affect the extraction of phenolic compounds in plant foods (Cai, 2004; Naczk \& Shahidi, 2004).

\subsection{Total Flavonoid Content}

The total Flavonoid Content (TFC) of mushroom extracts is shown in Table 2. There was significant $(\mathrm{p}<0.0001)$ three-way interaction for VARIETY X EXTRACTION SOLVENT X TREATMENT. The extraction solvent, treatment method, and the varieties of mushrooms had significant differences in the quantity of flavonoids in the samples.

TFC of Seafood mushrooms in fresh freeze-dried aqueous extracts was significantly $(\mathrm{p} \leq 0.05)$ higher $(2.89 \mu \mathrm{g}$ CE/100g DW) than sautéed aqueous extracts $(2.09 \mu \mathrm{g} \mathrm{CE} / 100 \mathrm{~g} \mathrm{DW})$ and oven-dried freeze-dried $(1.81 \mu \mathrm{g} \mathrm{CE} / 100 \mathrm{~g} \mathrm{DW})$ aqueous extracts. Similarly, White Button mushrooms had significantly $(\mathrm{p} \leq 0.05)$ higher TFC in fresh freeze-dried $(3.63 \mu \mathrm{g}$ CE/100g DW) compared to sautéed freeze-dried (3.12 $\mu \mathrm{g} \mathrm{CE} / 100 \mathrm{~g} \mathrm{DW})$ and oven-dried freeze-dried (2.37 $\mu \mathrm{g} \mathrm{CE} / 100 \mathrm{~g} \mathrm{DW})$ aqueous extracts. Portabella mushrooms had significantly $(\mathrm{p} \leq 0.05)$ lower TFC in fresh freeze-dried aqueous extracts $(1.55 \mu \mathrm{g} \mathrm{CE} / 100 \mathrm{~g} \mathrm{DW})$ than oven-dried freeze-dried $(1.63 \mu \mathrm{g} \mathrm{CE} / 100 \mathrm{~g} \mathrm{DW})$ and sautéed freeze-dried $(1.60 \mu \mathrm{g}$ CE/100g DW) aqueous extracts. Portabella mushrooms had significantly $(\mathrm{p} \leq 0.05)$ higher TFC in fresh freeze-dried methanol extracts $(1.72 \mu \mathrm{g}$ CE/100g DW) in comparison to sauteed freezedried $(1.20 \mu \mathrm{g} \mathrm{CE} / 100 \mathrm{~g} \mathrm{DW})$ and oven-dried freeze-dried (1.36 $\mu \mathrm{g} \mathrm{CE} / 100 \mathrm{~g} \mathrm{DW})$ methanol extracts. Portabella mushrooms had significantly $(\mathrm{p} \leq 0.05)$ higher TFC than White Button and Seafood mushrooms. Flavonoids are large secondary metabolites in plants. In the present study, flavonoid content was determined using the aluminum chloride ( $\mathrm{AlCl} 3)$ colorimetric method. $\mathrm{AlCl} 3$ forms stable acid complexes with the C-4 keto or hydroxyl group of the flavones and flavanols along with the dihydroxyl groups in the A and B ring of flavonoids. A study by Ramirez (2016) suggests the absence of flavonoid in mushrooms but some mushrooms may contain trace amounts of flavonoids from other plant. Mushrooms are parasitic in nature and may attach themselves to other plants to absorb nutrients because of which host plant produces secondary metabolites (flavonoids) that are harmful to mushrooms. This may be the reason for minute quantities of flavonoids in the mushroom samples.

\subsection{Antioxidant activity}

\subsubsection{FRAP (Ferric Reducing Antioxidant Potential)}

Table 3 shows Ferric Reducing Antioxidant Potential (FRAP) in five varieties [Portabella (P), Oyster (O), White Button (WBt), Seafood (SF), and White Beech (WBh)] of mushrooms with three different treatments fresh freeze-dried (F), sautéed freeze-dried $(\mathrm{S})$ and oven-dried freeze-dried (OD) dissolved in two different solvents aqueous (A) and methanol (M). There was significant $(\mathrm{p}<$ 0.0001) three-way interaction for VARIETY X EXTRACTION SOLVENT X TREATMENT. The extraction solvent, treatment method, and the varieties of mushrooms were significantly different in the ferric reducing antioxidant potential in the samples. FRAP was significantly ( $\mathrm{p} \leq 0.05)$ higher in PAOD $(980.42 \mathrm{mM} \mathrm{Fe}(\mathrm{II}) / 100 \mathrm{~g} \mathrm{DW})$ than PAS $(907.76 \mathrm{mM} \mathrm{Fe}(\mathrm{II}) / 100 \mathrm{~g}$ DW) and PAF (809.41 mM Fe (II)/100g DW). PMOD (261.12 mM Fe (II)/100g DW) had significantly $(\mathrm{p} \leq 0.05)$ highest FRAP followed by PMF (250.49 mM Fe (II)/100g DW) and PMS (210.61 mM Fe (II)/100g DW). OAF (769.54 mM Fe (II)/100g DW) had 
significantly ( $\mathrm{p} \leq 0.05)$ higher FRAP than OAOD $(697.77 \mathrm{mM} \mathrm{Fe}(\mathrm{II}) / 100 \mathrm{~g}$ DW) and OAS (688.91 mM Fe (II)/100g DW). The ferric reducing antioxidant potential was significantly $(\mathrm{p} \leq 0.05)$ higher in OMOD $(220.89 \mathrm{mM} \mathrm{Fe}(\mathrm{II}) / 100 \mathrm{~g} \mathrm{DW})$ than OMF (199.81 $\mathrm{mM} \mathrm{Fe}(\mathrm{II}) / 100 \mathrm{~g}$ DW) and OMS (158.16 mM Fe (II)/100g DW). White Button mushrooms had significantly $(\mathrm{p} \leq 0.05)$ higher reduction potential power for sautéed freeze-dried aqueous extracts $(362.84 \mathrm{mM} \mathrm{Fe}$ (II)/100g DW) compared to fresh freeze-dried (280.44 mM Fe (II)/100g DW) and oven-dried freeze-dried (183.68 mM Fe (II)/100g DW) aqueous extracts. Whereas methanol extracts of White Button mushrooms had shown opposite trend where sautéed freeze-dried methanol extracts $(94.37 \mathrm{mM} \mathrm{Fe}$ (II) $/ 100 \mathrm{~g} \mathrm{DW})$ had significantly $(\mathrm{p} \leq 0.05)$ lowest reduction potential compared to fresh freeze-dried $(228.69 \mathrm{mM} \mathrm{Fe}(\mathrm{II}) / 100 \mathrm{~g}$ DW) and oven-dried freeze-dried ( $242.69 \mathrm{mM} \mathrm{Fe}$ (II)/100g DW) methanol extracts. The same trend was followed by methanol extracts of Seafood (OD- $52.18 \mathrm{mM} \mathrm{Fe}$ (II)/100g DW, F- $50.97 \mathrm{mM} \mathrm{Fe}$ (II)/100g DW and S- $47.91 \mathrm{mM} \mathrm{Fe}$ (II)/100g DW) and White Beech mushrooms (OD- $80.19 \mathrm{mM}$ Fe (II)/100g DW, F- $74.42 \mathrm{mM} \mathrm{Fe}$ (II)/100g DW and S- $69.77 \mathrm{mM} \mathrm{Fe}$ (II)/100g DW). While aqueous extracts of Seafood and White Beech mushrooms resulted in significantly $(\mathrm{p} \leq 0.05)$ higher reducing potential by fresh freeze-dried samples (259.70- and 130.34-mM Fe (II)/100g DW) than sautéed freeze-dried (170.21- and 114.56-mM Fe (II)/100g DW) and oven-dried freeze-dried (55.74- and 105.88-mM Fe (II)/100g DW) samples. All the aqueous extracts had significantly $(\mathrm{p} \leq 0.05)$ higher reduction potential than methanol extracts in their respective treatments, varieties, and solvents.

\subsubsection{TEAC (Trolox Equivalent Antioxidant Capacity)}

Table 4 shows the Trolox equivalent antioxidant capacity (TEAC) in five varieties [Portabella (P), Oyster (O), White Button (WBt), Seafood (SF), and White Beech (WBh)] of mushrooms with three different treatments fresh freeze-dried (F), sautéed freezedried (S) and oven-dried freeze-dried (OD) dissolved in two different solvents aqueous (A) and methanol (M). There was significant $(\mathrm{p}<0.0001)$ three-way interaction for VARIETY X EXTRACTION SOLVENT X TREATMENT. The extraction solvent, treatment method, and the varieties of mushrooms had a significant difference in the Trolox Equivalent Antioxidant Capacity in the samples. Significantly $(\mathrm{p} \leq 0.05)$ higher TEAC was observed in fresh aqueous Portabella mushrooms $(56.61 \mu \mathrm{g}$ T.E/100g DW) as compared to PMOD, PAOD, PAS, PMS, and PMF (46.38, 45.41, 42.42, 37.59 and $18 \mu \mathrm{g}$ T.E/100g DW respectively). WBtMS $(58.25 \mu \mathrm{g}$ T.E/100g DW) had significantly $(\mathrm{p} \leq 0.05)$ highest TEAC followed by WBtMF, WBtMOD, WBtAOD, WBtAF, and WBtAS $(54.29,44.35,34.79,26.98$ and $22.73 \mu \mathrm{g}$ T.E/100g DW respectively). SFMOD (2.07 $\mu \mathrm{g}$ T.E/100g DW) had 24 to 16 folds lower TEAC compared to SFMF, SFAOD, SFMS, SFMF, and SFMS (50.33, 47.83, 42.9, 41.16, and $33.25 \mu \mathrm{g}$ T.E/100g DW respectively). White Beech mushrooms had significantly $(\mathrm{p} \leq 0.05)$ higher TEAC in MF extracts $(44.93 \mu \mathrm{g}$ T.E/100g DW) than MS (40.49 $\mu \mathrm{g}$ T.E/100g DW), AS (37.11 $\mu \mathrm{g}$ T.E/100g DW), AOD (33.44 $\mu \mathrm{g}$ T.E/100g DW), MOD (32.67 $\mu \mathrm{g}$ T.E/100g DW), and $\mathrm{AF}(21.47 \mu \mathrm{g}$ T.E/100g DW).

\subsubsection{NORS (Nitric Oxide Radical Scavenging)}

Nitric Oxide Radical Scavenging (NORS) in five varieties [Portabella (P), Oyster (O), White Button (WBt), Seafood (SF), and White Beech (WBh)] of mushrooms with three different treatments fresh freeze-dried (F), sauteed freeze-dried (S) and oven-dried freeze-dried (OD) dissolved in two different solvents aqueous (A) and methanol (M) is shown in Table 5. There was a significant $(\mathrm{p}<0.0001)$ three-way interaction for VARIETY X EXTRACTION SOLVENT X TREATMENT. The extraction solvent, treatment method, and the varieties of mushrooms had a significant difference in the Nitric Oxide Radical Scavenging in the samples. NORS for Portabella mushrooms was significantly $(\mathrm{p} \leq 0.05)$ higher in aqueous sautéed (AS) $(559.67 \mathrm{mM} \mathrm{NO} / 100 \mathrm{~g} \mathrm{DW})$ than aqueous oven-dried freeze-dried (AOD) and aqueous fresh freeze-dried (AF) extracts (392.33- and 338.33-mM NO/100g DW). Similar results for NORS were obtained in Oyster (AS- $277 \mathrm{mM}$ NO /100g DW, AOD- $240.33 \mathrm{mM}$ NO. /100g DW, and AF- 165.66 $\mathrm{mM} \mathrm{NO} / 100 \mathrm{~g}$ DW), White Button (AS- $216.33 \mathrm{mM}$ NO /100g DW, AOD- 127.2 mM NO. /100g DW, and AF- $46.93 \mathrm{mM} \mathrm{NO} / 100 \mathrm{~g}$ DW), Seafood (AS- 221.87 mM NO /100g DW, AOD- 127.13 mM NO. /100g DW, and AF- $55.26 \mathrm{mM} \mathrm{NO} / 100 \mathrm{~g}$ DW) and White Beech (AS- $110.6 \mathrm{mM}$ NO /100g DW, AOD- $70.6 \mathrm{mM}$ NO. /100g DW, and AF- $25.87 \mathrm{mM} \mathrm{NO/100g} \mathrm{DW).} \mathrm{Whereas} \mathrm{nitric} \mathrm{oxide}$ radical scavenging for Portabella mushrooms was significantly $(\mathrm{p} \leq 0.05)$ higher in methanol fresh freeze-dried (MF) $(201.12 \mathrm{mM}$ NO./100g DW) compared to methanol sautéed freeze-dried (MS) and methanol oven-dried freeze-dried (MOD) extracts (144.13 and $66 \mathrm{mg}$ F.A./100g DW). Similarly, NORS was significantly $(\mathrm{p} \leq 0.05)$ lower in heat-treated samples of Oyster $(\mathrm{MF}-188 \mathrm{mM}$ NO./100g DW, MS- $140.93 \mathrm{mM} \mathrm{NO/100g} \mathrm{DW,} \mathrm{MOD-} 33.53 \mathrm{mM} \mathrm{NO} / 100 \mathrm{~g}$ DW), White Button (MF- $124.73 \mathrm{mM} \mathrm{NO} . / 100 \mathrm{~g}$ DW, MS- $110.2 \mathrm{mM}$ NO/100g DW, MOD- $21.4 \mathrm{mM}$ NO./100g DW), Seafood (MF- $113.44 \mathrm{mM}$ NO./100g DW, MS- $98.09 \mathrm{mM}$ NO/100g DW, MOD- $19.6 \mathrm{mM} \mathrm{NO/100g} \mathrm{DW)} \mathrm{and} \mathrm{White} \mathrm{Beech} \mathrm{(MF-} 99.12 \mathrm{mM} \mathrm{NO} / 100 \mathrm{~g}$ DW, MS- $71.18 \mathrm{mM} \mathrm{NO} / 100 \mathrm{~g}$ DW, MOD- $14.32 \mathrm{mM}$ NO./100g DW) mushrooms. Methanol extracts for all the varieties of mushrooms showed significantly $(\mathrm{p} \leq 0.05)$ lower NORS than the aqueous extracts in their respective treatment methods except fresh Seafood and White Beech Mushroom extracts. Among all the varieties of mushrooms, Portabella mushrooms had significantly $(\mathrm{p} \leq 0.05)$ higher NORS followed by Oyster, White Button, Seafood, and White Beech mushrooms.

\section{Discussion}

A study by Sun et al. (2014) had shown higher reducing power in Boletus mushrooms when microwaved whereas, other cooking methods such as steaming, frying and boiling reduced the reducing capacity of mushrooms. A study by Barros et al. (2007) had shown that heat applied while cooking mushrooms can destroy the hydroxyl groups of phenolics. A study by Jacobs-Velzquez and Cisneros-Zevallos (2009) shows that heating may lead to decrease in antioxidant activity by change in the structure of the This publication is licensed under Creative Commons Attribution CC BY. 
phenolic compounds having higher antioxidant potential to other phenolic compounds that are weak antioxidants. A study by Sun et al. (2011) shows that cooking decreases the total phenolic content but also affected the amount of different phenolic compounds present in mushrooms which results in decrease of antioxidant activity when cooked at higher temperatures for longer time. A study by Hayat et al. (2009) had shown that destruction of cell walls and sub cellular compartments upon heating, aids in release of high amounts of antioxidant compounds which results in higher antioxidant activity of various fruits, vegetables, and mushrooms. Other studies (Jimnez-Monreal et al., 2009; Ju et al., 2010; Morales and Baabel, 2002) had suggested that the other possible reasons for increase in antioxidant activity of mushrooms during thermal processing are products of chemical reactions or Maillard reaction having higher radical scavenging activity.

\section{Conclusion \& Application}

The total phenolic content and antioxidant properties of mushrooms are affected by the higher cooking temperature and the length of time they were cooked. Sautéing was carried out for a shorter time of 10 minutes whereas, oven drying was carried out at same temperature for three hours and freeze drying did not employ higher temperature. Mushrooms showed higher phenolic content and antioxidant activity when sautéed and freeze dried as compared to when the fresh mushrooms were directly freeze dried. This is due to the release of potential antioxidant compounds from the cells after thermal destruction of cell wall. While there was decrease in total phenolic content and antioxidants when oven dried and freeze dried compared to freeze drying of fresh mushrooms. The reason behind this is loss of certain nutrients with moisture or due to structural changes in certain phenolic compounds present in mushrooms when kept at higher temperature for longer time. This study can help evaluate the processing temperature and time of mushrooms to improve their quality and minimize the loss of functionality of mushrooms. 


\section{Appendices}

Table 1: Total Phenolic content in Mushroom Extracts

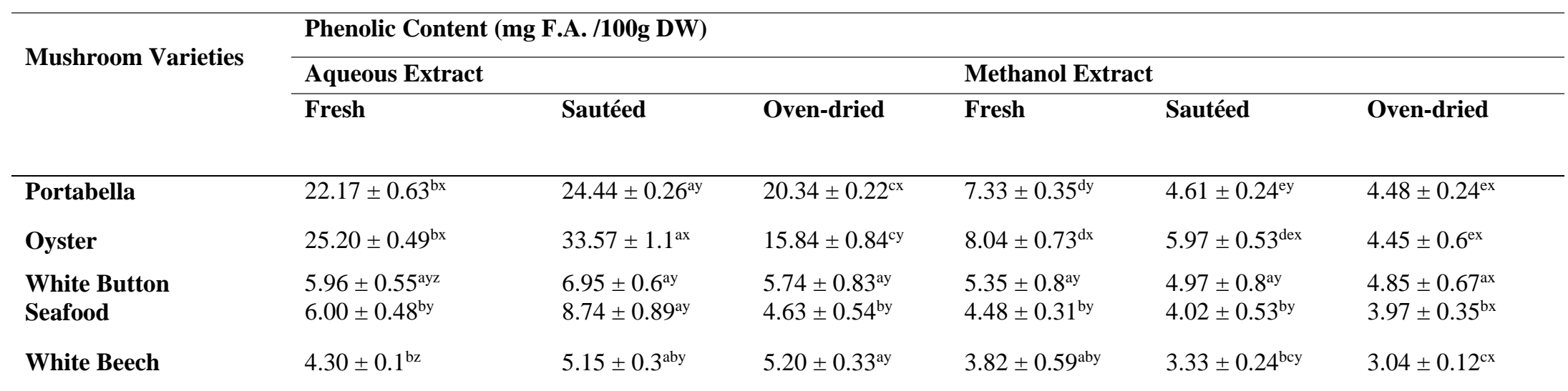

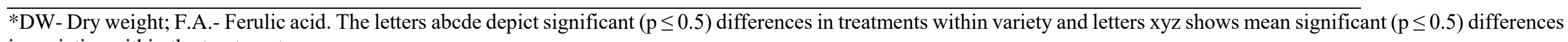
in varieties within the treatment group.

Table 2: Total Flavonoid Content (TFC) of mushroom Extracts

\begin{tabular}{|c|c|c|c|c|c|c|}
\hline \multirow{3}{*}{$\begin{array}{l}\text { Mushroom } \\
\text { Varieties }\end{array}$} & \multicolumn{6}{|c|}{ Total Flavonoid Content ( $\mu$ g CE/100g DW) } \\
\hline & \multicolumn{3}{|c|}{ Aqueous Extract } & \multicolumn{3}{|c|}{ Methanol Extract } \\
\hline & Fresh & Sautéed & Oven-dried & Fresh & Sautéed & Oven-dried \\
\hline Portabella & $1.55 \pm 0.01^{\mathrm{bz}}$ & $1.63 \pm 0.02^{\text {by }}$ & $1.60 \pm 0.03^{\mathrm{bz}}$ & $1.72 \pm 0.05^{\mathrm{ax}}$ & $1.20 \pm 0.04^{\mathrm{cz}}$ & $1.36 \pm 0.03^{\mathrm{cy}}$ \\
\hline Oyster & $1.86 \pm 0.04^{\text {by }}$ & $1.15 \pm 0.6^{\mathrm{cz}}$ & $1.86 \pm 0.09^{\mathrm{bxy}}$ & $1.12 \pm 0.04^{\mathrm{cyz}}$ & $1.13 \pm 0.03^{\mathrm{cz}}$ & $2.13 \pm 0.05^{\mathrm{ax}}$ \\
\hline White Button & $3.63 \pm 0.05^{\mathrm{aw}}$ & $3.12 \pm 0.06^{\mathrm{bw}}$ & $2.37 \pm 0.01^{\mathrm{cw}}$ & $1.05 \pm 0.003^{\mathrm{d} z}$ & $1.79 \pm 0.04^{\mathrm{dw}}$ & $1.03 \pm 0.005^{\mathrm{dz}}$ \\
\hline Seafood & $2.89 \pm 0.06^{\mathrm{ax}}$ & $2.09 \pm 0.03^{\mathrm{cx}}$ & $1.81 \pm 0.01^{\mathrm{dy}}$ & $1.27 \pm 0.03^{\mathrm{ey}}$ & $1.24 \pm 0.02^{\mathrm{eyz}}$ & $2.48 \pm 0.02^{\mathrm{bw}}$ \\
\hline White Beech & $1.48 \pm 0.01^{\mathrm{cz}}$ & $1.76 \pm 0.03^{\text {by }}$ & $2.21 \pm 0.01^{\mathrm{awx}}$ & $1.90 \pm 0.05^{\mathrm{bw}}$ & $1.38 \pm 0.02^{\mathrm{cxy}}$ & $1.43 \pm 0.06^{\mathrm{cy}}$ \\
\hline
\end{tabular}

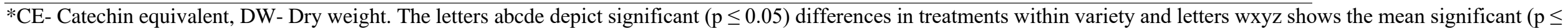
0.05 ) differences in varieties within the treatment group.

Table 3: Ferric Reducing Antioxidant Potential (FRAP) of Mushroom Extracts

\section{FRAP activity (mM Fe (II)/100g DW)}




\begin{tabular}{|c|c|c|c|c|c|c|}
\hline \multirow{2}{*}{$\begin{array}{l}\text { Mushroom } \\
\text { Varieties }\end{array}$} & \multicolumn{3}{|l|}{ Aqueous } & \multicolumn{3}{|l|}{ Methanol } \\
\hline & Fresh & Sautéed & Oven-Dried & Fresh & Sautéed & Oven-Dried \\
\hline Portabella & $809.41 \pm 6.21^{\mathrm{cw}}$ & $907.76 \pm 8.43^{\text {bw }}$ & $980.42 \pm 8.94^{\mathrm{av}}$ & $250.49 \pm 2.15^{\mathrm{ew}}$ & $210.61 \pm 2.54^{\mathrm{fw}}$ & $261.12 \pm 2.21^{\mathrm{dw}}$ \\
\hline Oyster & $769.54 \pm 5.80^{\mathrm{ax}}$ & $688.91 \pm 5.38^{b x}$ & $697.77 \pm 5.56^{\mathrm{bw}}$ & $199.81 \pm 1.23^{\mathrm{cx}}$ & $158.16 \pm 1.86^{\mathrm{dx}}$ & $220.89 \pm 2.81^{\mathrm{cx}}$ \\
\hline White Button & $280.44 \pm 3.15^{\text {by }}$ & $362.84 \pm 3.4^{\text {ay }}$ & $183.68 \pm 2.8^{\mathrm{ex}}$ & $228.69 \pm 2.88^{\mathrm{dwx}}$ & $94.37 \pm 0.84^{\text {fy }}$ & $242.69 \pm 2.91^{\mathrm{cwx}}$ \\
\hline White Beech & $130.34 \pm 1.63^{\mathrm{az}}$ & $114.56 \pm 1.16^{\mathrm{bz}}$ & $105.88 \pm 0.98^{\text {by }}$ & $74.42 \pm 0.7^{\text {cdy }}$ & $69.77 \pm 0.67^{\mathrm{dyz}}$ & $80.19 \pm 0.72^{\text {cy }}$ \\
\hline
\end{tabular}

$\begin{array}{lllllll}\text { White Beech } & 130.34+1.63^{\mathrm{az}} & 114.56 \pm 1.16^{\mathrm{bz}} & 105.88 \pm 0.98^{\text {by }} & 74.42 \pm 0.7^{\mathrm{cdy}} & 69.77 \pm 0.67^{\mathrm{dyz}} & 80.19 \pm 0.72^{\mathrm{cy}}\end{array}$

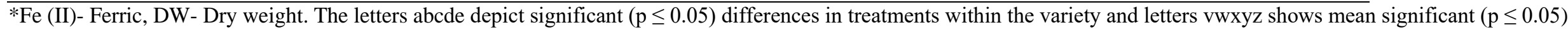
differences in varieties within the treatment group. 
Table 4: Trolox Equivalent Antioxidant Capacity (TEAC) of Mushroom Extracts

\begin{tabular}{|c|c|c|c|c|c|c|}
\hline \multirow{3}{*}{$\begin{array}{l}\text { Mushroom } \\
\text { Varieties }\end{array}$} & \multicolumn{6}{|c|}{ TEAC ( $\mu$ g T.E. /100g DW) } \\
\hline & \multicolumn{3}{|c|}{ Aqueous extract } & \multicolumn{3}{|c|}{ Methanol extract } \\
\hline & Fresh & Sautéed & Oven-dried & Fresh & Sautéed & Oven-dried \\
\hline Portabella & $56.61 \pm 1.04^{\mathrm{va}}$ & $42.42 \pm 0.79^{\mathrm{cw}}$ & $45.41 \pm 0.87^{\mathrm{xb}}$ & $18 \pm 0.33^{\mathrm{dz}}$ & $37.59 \pm 0.69^{\mathrm{bz}}$ & $46.38 \pm 0.89^{\mathrm{xb}}$ \\
\hline Oyster & $6.80 \pm 0.09^{\mathrm{az}}$ & $40.49 \pm 0.73^{\mathrm{dw}}$ & $61.53 \pm 1.09^{\mathrm{ew}}$ & $56.6 \pm 1.03^{b w}$ & $43.87 \pm 0.81^{\mathrm{cx}}$ & $62.40 \pm 1.1^{\text {aw }}$ \\
\hline White Button & $34.79 \pm 0.6^{\mathrm{dx}}$ & $22.73 \pm 0.48^{\mathrm{fz}}$ & $26.98 \pm 0.53^{\mathrm{ez}}$ & $54.29 \pm 0.92^{\mathrm{bw}}$ & $58.25 \pm 0.96^{\mathrm{aw}}$ & $44.35 \pm 0.85^{\mathrm{cx}}$ \\
\hline Seafood & $41.16 \pm 0.77^{\mathrm{dw}}$ & $33.25 \pm 0.6^{\mathrm{ey}}$ & $47.83 \pm 0.9^{b x}$ & $50.33 \pm 0.9^{\mathrm{ax}}$ & $42.90 \pm 0.79^{\mathrm{cxy}}$ & $2.07 \pm 0.03^{\mathrm{fz}}$ \\
\hline White Beech & $21.47 \pm 0.49^{\mathrm{ey}}$ & $37.11 \pm 0.68^{\mathrm{cx}}$ & $33.44 \pm 0.6^{\mathrm{dy}}$ & $44.93 \pm 0.86^{\mathrm{ay}}$ & $40.49 \pm 0.72^{\text {byz }}$ & $32.67 \pm 0.59^{\mathrm{dy}}$ \\
\hline
\end{tabular}

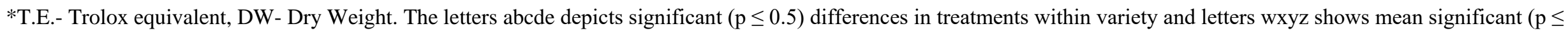
$0.5)$ differences in varieties within the treatment group. 
Table 5 Nitric Oxide Radical Scavenging (NORS) in selected Mushroom Extracts

\begin{tabular}{|c|c|c|c|c|c|c|}
\hline \multirow{3}{*}{$\begin{array}{l}\text { Mushroom } \\
\text { Varieties }\end{array}$} & \multicolumn{6}{|c|}{ NORS (mM NO/100g DW) } \\
\hline & \multicolumn{3}{|l|}{ Aqueous extract } & \multicolumn{3}{|c|}{ Methanol extract } \\
\hline & Fresh & Sautéed & Oven-dried & Fresh & Sautéed & Oven-dried \\
\hline Portabella & $338.33 \pm 3.09^{\mathrm{cw}}$ & $559.67 \pm 4.43^{\text {aw }}$ & $392.33 \pm 3.94^{\mathrm{bw}}$ & $201.12 \pm 2.12^{\mathrm{dv}}$ & $144.13 \pm 1.95^{\mathrm{ew}}$ & $66 \pm 0.84^{\mathrm{fw}}$ \\
\hline White Button & $46.93 \pm 1.37^{\mathrm{dy}}$ & $216.33 \pm 2.19^{a y}$ & $127.2 \pm 1.78^{\text {by }}$ & $124.73 \pm 1.7^{\mathrm{bx}}$ & $110.2 \pm 1.67^{\mathrm{cx}}$ & $21.4 \pm 0.4^{\mathrm{ey}}$ \\
\hline Seafood & $55.26 \pm 1.4^{\mathrm{ey}}$ & $221.87 \pm 2.24^{\mathrm{ay}}$ & $127.13 \pm 1.78^{\text {by }}$ & $113.44 \pm 1.69^{\text {cy }}$ & $98.09 \pm 1.59^{\mathrm{dy}}$ & $19.6 \pm 0.27^{\text {fy }}$ \\
\hline White Beech & $25.87 \pm 1.28^{\mathrm{dz}}$ & $110.6 \pm 1.67^{\mathrm{az}}$ & $70.6 \pm 1.42^{\mathrm{cz}}$ & $99.12 \pm 1.6^{\mathrm{bz}}$ & $71.18 \pm 1.44^{\mathrm{cz}}$ & $14.32 \pm 0.19^{\mathrm{ez}}$ \\
\hline
\end{tabular}

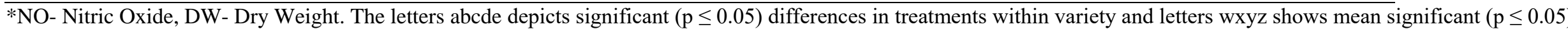
difference in varieties within the treatment group. 


\section{References}

1. Agrahar-Murugkar, D., \& Subbulakshmi, G. (2005). Nutritional value of edible wild mushrooms collected from the Khasi hills of Meghalaya. Food Chemistry, 89(4), 599603.

2. Barros, L., Calhelha, R. C., Vaz, J. A., Ferreira, I. C., Baptista, P., \& Estevinho, L. M. (2007). Antimicrobial activity and bioactive compounds of Portuguese wild edible mushrooms methanolic extracts. European Food Research and Technology, 225(2), 151-156.

3. Breheret, S., Talou, T., Rapior, S., \& Bessière, J. M. (1997). Monoterpenes in the aromas of fresh wild mushrooms (Basidiomycetes). Journal of Agricultural and Food Chemistry, 45(3), 831-836.

4. Çağlarırmak, N. (2007). The nutrients of exotic mushrooms (Lentinula edodes and Pleurotus species) and an estimated approach to the volatile compounds. Food chemistry, $105(3), 1188-1194$.

5. Cheah, I. K., Tang, R. M., Yew, T. S., Lim, K. H., \& Halliwell, B. (2017). Administration of pure ergothioneine to healthy human subjects: uptake, metabolism, and effects on biomarkers of oxidative damage and inflammation. Antioxidants \& redox signaling, 26(5), 193-206.

6. Chen, H. K. (1986). Studies on the characteristics of taste-active components in mushroom concentrate and its powderization. Master's Thesis, National Chung-Hsing University, Taichung, Taiwan.

7. Cho, I. H., Choi, H. K., \& Kim, Y. S. (2006). Difference in the volatile composition of pine-mushrooms (Tricholoma matsutake Sing.) according to their grades. Journal of agricultural and food chemistry, 54(13), 4820-4825.

8. Dermiki, M., Phanphensophon, N., Mottram, D. S., \& Methven, L. (2013). Contributions of non-volatile and volatile compounds to the umami taste and overall flavour of shiitake mushroom extracts and their application as flavour enhancers in cooked minced meat. Food chemistry, 141(1), 77-83.

9. Friedman, M. (2015). Chemistry, nutrition, and health-promoting properties of Hericium erinaceus (lion's mane) mushroom fruiting bodies and mycelia and their bioactive compounds. Journal of agricultural and food chemistry, 63(32), 7108-7123.

10. Grosshauser, S., \& Schieberle, P. (2013). Characterization of the key odorants in pan-fried white mushrooms (Agaricus bisporus L.) by means of molecular sensory science: comparison with the raw mushroom tissue. Journal of agricultural and food chemistry, 61(16), 3804-3813.

11. Guidry, L. A. (2012). Analysis of Ergothioneine Production in Mycobacterium Tuberculosis (Doctoral dissertation, University of Alabama at Birmingham).

12. Halliwell, B., Cheah, I. K., \& Tang, R. M. (2018). Ergothioneine-a diet-derived antioxidant with therapeutic potential. Febs Letters, 592(20), 3357-3366.

13. Heleno, S. A., Barros, L., Sousa, M. J., Martins, A., \& Ferreira, I. C. (2010). Tocopherols composition of Portuguese wild mushrooms with antioxidant capacity. Food chemistry, 119(4), 1443-1450.

14. Heleno, S. A., Barros, L., Sousa, M. J., Martins, A., \& Ferreira, I. C. (2010). Tocopherols composition of Portuguese wild mushrooms with antioxidant capacity. Food chemistry, 119(4), 1443-1450.

15. Hong, J. S., Kim, Y. H., Lee, K. R., Kim, M. K., Cho, C. I., Park, K. H., ... \& Lee, J. B. (1988). Composition of organic acid and fatty acid in Pleurotus ostreatus, Lentinus edodes and Agaricus bisporus. Korean J Food Sci Technol, 20(1), 100-106. 


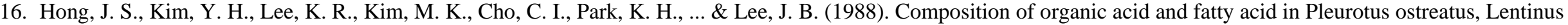
edodes and Agaricus bisporus. Korean J Food Sci Technol, 20(1), 100-106.

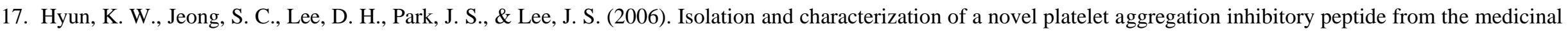
mushroom, Inonotus obliquus. Peptides, 27(6), 1173-1178.

18. Jong, S. C., \& Birmingham, J. M. (1993). Mushrooms as a source of natural flavor and aroma compounds. Mushroom biology and mushroom products, $345-366$.

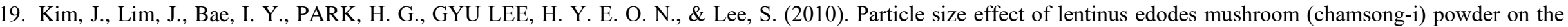
physicochemical, rheological, and oil-resisting properties of frying batters. Journal of texture studies, 41(3), 381-395.

20. Li, W., Gu, Z., Yang, Y., Zhou, S., Liu, Y., \& Zhang, J. (2014). Non-volatile taste components of several cultivated mushrooms. Food chemistry, 143, 427-431.

21. Li, W., Gu, Z., Yang, Y., Zhou, S., Liu, Y., \& Zhang, J. (2014). Non-volatile taste components of several cultivated mushrooms. Food chemistry, 143, 427-431.

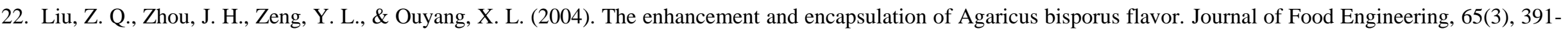
396.

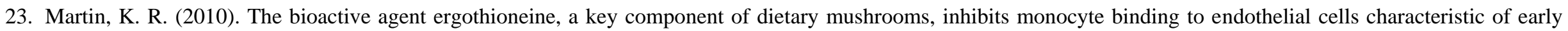
cardiovascular disease. Journal of medicinal food, 13(6), 1340-1346.

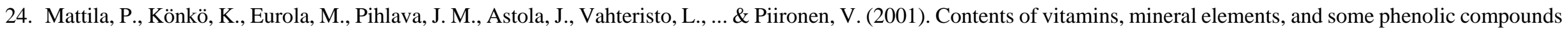
in cultivated mushrooms. Journal of agricultural and food chemistry, 49(5), 2343-2348.

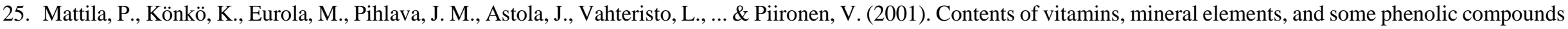
in cultivated mushrooms. Journal of agricultural and food chemistry, 49(5), 2343-2348.

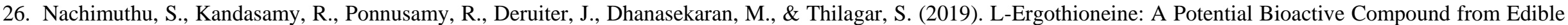
Mushrooms. In Medicinal Mushrooms (pp. 391-407). Springer, Singapore.

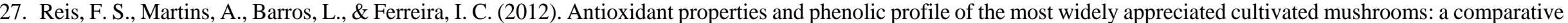
study between in vivo and in vitro samples. Food and Chemical Toxicology, 50(5), 1201-1207.

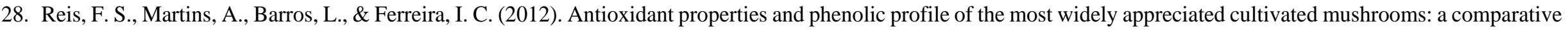
study between in vivo and in vitro samples. Food and Chemical Toxicology, 50(5), 1201-1207.

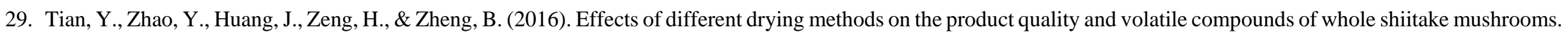
Food Chemistry, 197, 714-722.

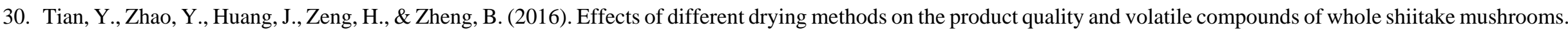
Food Chemistry, 197, 714-722.

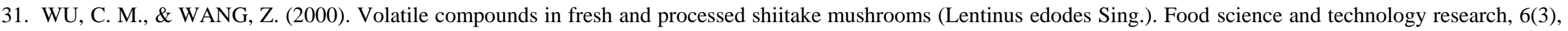
166-170.

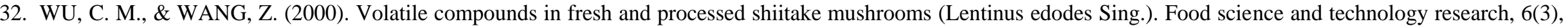
$166-170$. 
33. Yang, W., Yu, J., Pei, F., Mariga, A. M., Ma, N., Fang, Y., \& Hu, Q. (2016). Effect of hot air drying on volatile compounds of Flammulina velutipes detected by HSSPME-GC-MS and electronic nose. Food chemistry, 196, 860-866. 